\title{
COVID-19 A Pure Gamble \\ An Engineering perspective
}

\author{
Ho Teck Tuak, PhD. \\ Keywords: COVID-19, Easing Of Measures, Area-Mitigation
}

\begin{abstract}
States around the world contemplate easing the control measures whether all at once or in phases and so allow businesses to freely open and population freely moving about. Some places have actually done so and are now facing the consequences. Authority is under pressure to revive the economy but such actions are only taking a pure-play at gamble. Without doing area-mitigation first and having population walking about as though it is pre-virus era is simply having population walking right into minefields. It is now well known that there are patients with asymptomatic conditions or no symptoms who are spreaders, there are symptomatic patients walking about, there are live viruses sticking on surfaces likely at many places, and there are aerosols lingering in the air at unknown places. And there are new clusters still appearing and community spreading in progress. It is likely more effective and less of a gamble to counter most of the physical conditions first before easing the measures. This not only eliminates the Virus as much as possible and also able to instil a sense of confidence to the population to participate in the easing.
\end{abstract}

As populations around the world have taken steps to wear protective masks, but why are there still new infections clusters appearing. What is likely causing the problems are aerosols and some large droplets are unintentionally driven into airborne. It is likely the Virus is leaving or entering hosts through secondary pathways for example skin absorption. It is likely is the last frontier to disinfect the entire area to remove as much as possible aerosols and large droplets in the air and on surfaces. One way is to fumigate the entire area using safe disinfectant in gaseous form. And all buildings are required to open the windows to let in the fumigation gas. One way is to use airplanes spraying the fumigation gas. The other ways are using motor vehicles running through the streets or portable units operate by humans or robots. Water-based disinfectant is likely counter-effective because it will likely create secondary problems such as bacteria problems or the fusion of bacteria with virus problems. This fumigation is expected to be effective if it is performed at least once and repeated if necessary, until the situation improves. As gas will rise into the atmosphere some additives are added to cause it to remain at ground level for sometimes. The disinfectant chosen is likely to be effective if it can affect oil molecules. One of such gasses is Sulfuryl fluoride, and its use at extremely low PPM is likely toxic enough to the Virus and is safe for humans and most environments except those with allergic reactions that may need exceptional protection. Powerful countries already have the availability of such equipment can offer such humanitarian assistance to other countries without such equipment. Without doing area-mitigation first, it is likely discovering it is a case of penny-wise pound-foolish. 